\section{Research Square}

Preprints are preliminary reports that have not undergone peer review.

They should not be considered conclusive, used to inform clinical practice, or referenced by the media as validated information.

\title{
Temporal and Spatial Characterization of Sediment Bacterial Communities From Lake Wetlands in a Plain River Network Region
}

\author{
Wei Huang ( $\triangle$ yixinghd6@163.com) \\ Donghua University \\ Chengqi Tu \\ Donghua University \\ Zhenghai Jin \\ Donghua University \\ Haoran Yang \\ Donghua University \\ Changyu Lu \\ Hebei GEO University \\ Jiao Dong \\ Chinese Research Academy of Environmental Sciences \\ Kun Wang \\ Chinese Research Academy of Environmental Sciences
}

\section{Research Article}

Keywords: Bacterial community, Lake wetland, Sediment, Seasonal variation

Posted Date: December 1st, 2021

DOI: https://doi.org/10.21203/rs.3.rs-1042496/v1

License: (c) (i) This work is licensed under a Creative Commons Attribution 4.0 International License. Read Full License 


\section{Abstract}

Sediment bacterial communities are a vital component of microbial communities in aquatic and terrestrial ecosystems and they play a critical role in lake wetlands. To investigate the effect of season, depth and regional environmental factors on the composition and diversity of bacterial communities in lake wetland sediments, the millions of Illumina reads (16S rRNA gene amplicons) from sediment bacterial communities in different seasons were examined using a technically consistent approach. Results from diversity index, relative abundance, principal component analysis (PCA), redundancy analysis (RDA) and linear discriminant analysis effect size (LEfSe) analysis indicated that the diversity of the bacterial community in summer was generally higher than in other seasons. Proteobacteria was the most abundant phylum in the sediment samples in different seasons $(43.15 \%-57.41 \%)$ and different layers $(39.66 \%-77.97 \%)$; the autumn sediments were enriched with Firmicutes (5.67\%) and Chloroflexi (12.5\%); in all four seasons the sediments were enriched with Betaproteobacteria (14.98\%-23.45\%), Gammaproteobacteria (11.98\%-14.36\%) and Deltaproteobacteria (8.68\%-14.45\%). In the bottom sediments (10-25 cm) Chloroflexi were abundant (average value $10.42 \%$ ), while Bacteroidetes was the dominant phylum in the surface sediments; and redundancy analysis found that total phosphorus (TP) $(P=0.036)$ was the main environmental factor influencing the sediment bacterial community in different layers. This study provides a reference for further understanding the effects of seasonal changes on sediment microorganisms in lake wetlands.

\section{Introduction}

In plain river network regions, the lake wetland is a special wetland type that includes wetland plants, microbes and animals, and these play an important ecological role in flood storage, water purification, habitat maintenance and maintaining species diversity (Arias et al., 2014, Bunn et al., 2010, Newman, 2011). Bacterial communities are prevalent in lake wetlands and play key roles in ecosystem functions (Newton et al., 2011). Sediments are a unique element in aquatic ecosystems and have significantly higher microbial species and diversity than the overlying water (Wang et al., 2012). Sediment bacterial communities are a vital component of microbial communities in aquatic and terrestrial ecosystems, and participate in the biogeochemical cycles of carbon, nitrogen, sulfur and other elements, thereby contributing to the recovery and maintenance of the health and balance of aquatic and terrestrial ecosystems (Yang et al., 2016). Sediment bacterial communities are the drivers of nutrient cycling and energy conversion in aquatic ecosystems, and changes in microbial physiological functions affect nutrient formation and cycling in sediments, which can lead to secondary pollution of water and lake eutrophication (Wan et al., 2017, Zhang et al., 2019a). Bacterial diversity is an important index for water quality evaluation, which can reflect water quality and the migration and transformation of pollutants in sediments (de Oliveira and Margis, 2015, Zhang et al., 2019b).

The functional diversity of microbes is influenced by environmental factors. Numerous studies of the bacterial communities in lake wetland ecosystems have shown that they are closely related to a variety of environmental factors, such as $\mathrm{C}$ and $\mathrm{N}$ availability, temperature and sediment structure characteristics (Liu et al., 2012, Cookson et al., 2008, Mackelprang et al., 2011, Lin et al., 2012, Hall et al., 2008, Redmond and Valentine, 2012, Moseman-Valtierra et al., 2010). Furthermore, the organic matter (OM) content affects the structure and function of sediment communities (Mayor et al., 2012). There are differences in the physical and chemical indexes of the biogeochemical properties of the sediments, owing to the influence of spatial and seasonal factors (Song et al., 2012, Zhang et al., 2019a). Some studies have shown that sediment bacterial community structure and composition are characterized by significant seasonal and temporal variations (Song et al., 2012, Wang et al., 2012, Schwarz et al., 2007). Because of the sensitivity of sediment bacteria to small chemical and physical changes, their structure may change spatially and temporally in response to environmental variations. Season is one of the key factors affecting sediment bacterial communities (Obi et al., 2016). The spatial heterogeneity of bacterial community richness and diversity in sediments has an impact on water quality (Yu et al., 2015, Chen et al., 2015). There has, however, been limited exploration of the changes in the bacterial community with respect to environmental variability (season) and vertical distribution (depth) in lake wetlands.

We investigated the bacterial communities in the sediments of a plain river network area in all four seasons, focusing particularly on the vertical microbial biomass of sediment samples from six typical sites in summer. Our main aim was to understand the spatiotemporal variation in the bacterial communities and to identify the driving factors at different locations in the lake wetland. Seasonal changes in the composition and diversity of microbes were analyzed by constructing clone libraries of 16S rRNA, from which potential reasons for differences in community structure were inferred. Our results provide a new perspective on and valuable reference to the bacterial community in shallow, eutrophic lake wetlands, which we hope can be applied to other shallow and eutrophic aquatic ecosystems.

\section{Material And Methods}

\subsection{Sediment sampling}

Thirty sampling sites were chosen in a plain river network (Fig. 1), and the surface sediment samples were collected from these sites in spring (March), summer (June), autumn (September) and winter (December). A total of 120 sediment samples was obtained over the four seasons: spring (A), summer (B), autumn (C) and winter (D). We divided the sediment samples from six typical sites $(3,10,14,18,19,20)$ in summer into 
five layers $(0-5,5-10,10-15,15-20,20-25 \mathrm{~cm})$, and 30 sediment samples were collected. The sediment samples were homogenized and stored in sealed plastic bags, and placed immediately onto dry ice. All samples were transferred to the laboratory within $24 \mathrm{~h}$ and kept at $-80^{\circ} \mathrm{C}$ until processing. Water samples from the 30 sites were also collected for analysis of the influence of environmental factors on bacterial communities in the sediments.

\subsection{Geochemical analysis}

The total nitrogen (TN) and total phosphorus (TP) of each sediment were measured by using standardized methods and tests (Huang et al., 2017). The organic matter (OM) content of each sediment was calculated according to the loss on ignition to constant mass $(4 \mathrm{~h})$ at $550^{\circ} \mathrm{C}$ (Huang et al., 2015). The main properties of the sediment samples are shown in Fig. 2.

\subsection{DNA extraction, PCR amplification, and sequencing}

DNA was extracted from the sediment samples using a PowerSoil DNA Isolation Kit (Mobio Laboratories Inc., San Diego, CA, USA), following the manufacturer's manual. DNA concentration and purity were checked using a NanoDrop Spectrophotometer (Thermo Scientific NanoDrop

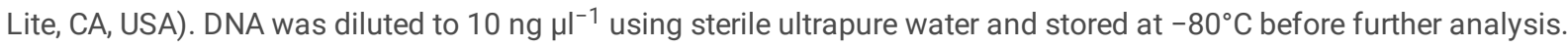

The specific primers 515F (GTGCCAGCMGCCGCGGTAA) and 926R (CCGTCAATTCMTTTRAGTTT) were used in PCR amplification of bacterial 16S rRNA V4-V5 regions. We chose these primers because of their high coverage of almost all common phyla (Liu et al., 2008, Wang and Qian, 2009). Each PCR mixture $(25 \mu \mathrm{l})$ included $1 \times \mathrm{PCR}$ buffer, $1.5 \mathrm{mmol} \mathrm{L}^{-1} \mathrm{MgCl} 2,0.4 \mu \mathrm{mol} \mathrm{L}^{-1}$ of deoxynucleoside triphosphate, $1.0 \mu \mathrm{mol} \mathrm{L}^{-1}$ of each primer, $0.5 \mathrm{U}$ of TaKaRa Ex Taq DNA polymerase and $10 \mathrm{mg}$ of template DNA. The conditions for PCR amplification were: initial denaturation at $94^{\circ} \mathrm{C}$ for $1 \mathrm{~min}, 30 \mathrm{cycles}$ (denaturation at $94^{\circ} \mathrm{C}$ for $20 \mathrm{~s}$, annealing at $56^{\circ} \mathrm{C}$ for $30 \mathrm{~s}$ and elongation at $72^{\circ} \mathrm{C}$ for $45 \mathrm{~s}$ ) and a final extension at $72^{\circ} \mathrm{C}$ for $5 \mathrm{~min}$. Three replicate PCR reactions were performed for each sample. A similar volume of $1 \times$ loading buffer (containing SYBR green) was mixed with the PCR products and then the PCR product size was detected by $2 \%$ agarose gel electrophoresis. Samples presenting a bright main strip of 300-500 bp were selected for further experiments. PCR products were gel purified using an OMEGA gel extraction kit (Omega Bio-Tek, USA), and equal molar amounts of the products were pooled from different samples. The TruSeq DNA PCR-Free Sample Prep Kit (Illumina) was used to generate sequencing libraries according to the manufacturer's instructions, and index codes were added. Library quality was evaluated on a Qubit $\AA_{2} .0$ Fluorometer (Thermo Scientific, CA, USA) and Agilent Bioanalyzer 2100 system. Eventually, the library was subjected to paired-end sequencing $(2 \times 250$ bp) on an Illumina MiSeq platform from Tiny Gene Bio-Tech Co., Ltd. (Shanghai).

\subsection{Data and statistical analysis}

The richness estimators (Chao and Abundance-based Coverage Estimator (ACE)) and the diversity indices (Shannon and Simpson) were calculated. Principal component analysis (PCA) was employed to explore and visualize the similarities between sediment samples obtained from four seasons based on Bray-Curtis dissimilarity using the package Ape (Paradis et al., 2004). Canoco5 software was used to carry out redundancy analysis (RDA) based on population abundance and environmental factors. The sediment samples with specific indicator groups of bacteria were found using LEfSe (Linear discriminant analysis Effect Size) (Segata et al., 2011). Independent T-test and permutational multivariate analysis of variance were used to determine the differences that exist among different groups.

\subsection{Accession numbers}

All of the sequencing data analyzed in this study can be downloaded from the NCBI's Sequence Read Archive using the accession numbers SRP314068 for samples from four seasons (120 samples) and five layers (30 samples) in lake wetlands.

\section{Result}

\subsection{Spatial distribution of the main pollutants}

The chemical parameters of water and sediment samples varied by different regions in the plain river network region (Fig. 2). In general, there was no significant change in the mean concentrations of TN, TP and OM in sediment samples from the lake wetlands over the four seasons. Relatively high levels of TN, TP and OM in sediment samples from six typical sampling sites $(3,10,14,18,19,20)$ were found in summer (Fig. 2).

\subsection{Diversity indices}

One hundred and twenty sediment samples were collected from the lake wetlands in four seasons. A total of $6,234,741$ reads was obtained after tag merge and quality control. Table 1 shows the diversity indices of the sediment samples from the four seasons. The sediment samples from summer and autumn had a greater diversity than those from the other seasons. The sediment samples in summer had the highest Chao 
(4825) and ACE (5276) indices, while the sediment samples in spring had the lowest Chao (4282) and ACE (5166) indices. The Shannon values of the sediment samples over the four seasons showed a similar trend in variation.

Table 1

Diversity indices of the sediment samples from the four seasons (A for spring, B for summer, C for autumn and D for winter)

\begin{tabular}{|lllll|}
\hline Sample type & \multicolumn{2}{l}{ Diversity } & \\
\cline { 2 - 5 } & Chao & ACE & Shannon & Simpson \\
\hline A & 4282 & 5166 & 5.84 & 0.016 \\
\hline B & 4825 & 5276 & 6.19 & 0.014 \\
C & 4581 & 5172 & 6.18 & 0.012 \\
\hline D & 4308 & 5271 & 6.09 & 0.010 \\
\hline
\end{tabular}

Sediment samples from six typical sampling sites $(3,10,14,18,19,20)$ were chosen, and the samples from each site were divided into five layers $(0-5,5-10,10-15,15-20,20-25 \mathrm{~cm})$. Figure 3 shows the diversity indices of the sediment samples from different layers. The results indicated that most of the sediment samples from the surface layer $(0-10 \mathrm{~cm})$ had greater diversity (Chao, ACE, Shannon) than the sediment samples from the bottom layer $(15-20 \mathrm{~cm})$. The surface $(0-5 \mathrm{~cm})$ sediment samples from site 3 had the lowest Chao, ACE and Shannon values than the sediment samples from other layers, and the bottom sediment $(20-25 \mathrm{~cm})$ samples had the highest Simpson value (0.06). Sediment samples from site 18 had a greater diversity than the other sediment samples, and sediment samples from the 5-10 $\mathrm{cm}$ layer had the highest Chao (3765), ACE (3745) and Shannon (6.2).

\subsection{Temporal and spatial comparisons of sediment bacterial community based on taxonomy}

The taxonomic assignment results indicated that there were 22 phyla and 29 classes (total percentage $>95 \%$ ) at the $97 \%$ sequence identity level (Fig. 4). Figure 4(a) shows the main phyla with high relative abundance $(>0.1 \%$ ) in sediment samples from the four seasons. Proteobacteria had the highest relative abundance (43.15-57.41\%) in the sediment samples from four seasons. At the phylum level, the bacterial community was also largely dominated by Bacteroidetes (12.14-18.08\%), Chloroflexi (6.19-12.50\%), Acidobacteria (2.94-4.71\%), Ignavibacteriae (1.38-2.60\%), Nitrospirae (1.82-3.68\%) and Firmicutes (1.33-5.67\%), and contained a small amount of, for example, Chlorobi, Aminicenantes, Verrucomicrobia, and Spirochaetae. Chloroflexi was more abundant in the sediments from summer (9.3\%) and autumn (12.5\%), and the sediment samples from summer had the most abundant Nitrospirae (3.68\%). The sediment samples from autumn also had more abundant Firmicutes (5.67\%) and Actinobacteria (2.61\%).

The changes in the bacterial community at the class level are shown in Fig. 4(b). Betaproteobacteria (14.98-23.45\%), Gammaproteobacteria (11.98-14.36\%), Deltaproteobacteria (8.68-14.45\%), Alphaproteobacteria (1.18-4.04\%) and Epsilonproteobacteria (0.70-1.64\%) were the more abundant classes of the Proteobacteria. Such classes as Flavobacteriia, Bacteroidia, Holophagae, Nitrospira, and Anaerolineae were also the main classes in the sediment samples from the four seasons. The sediment samples from winter and spring had more Betaproteobacteria than in summer and autumn, while the sediments had the most abundant Deltaproteobacteria (14.45\%). Nitrospira in the sediment samples from summer was also more abundant (3.68\%) than in the three other seasons.

The bacterial composition of the six typical sediments in different layers is shown in Fig. 5. Proteobacteria was still the most abundant (39.66$77.97 \%)$ phylum in the different layers of the sediments. The surface sediments $(0-15 \mathrm{~cm})$ in sites 14,18 and 20 had more Proteobacteria than the bottom sediments $(15-25 \mathrm{~cm})$, while the bottom sediments $(20-25 \mathrm{~cm})$ had more Proteobacteria than the surface sediments $(0-10 \mathrm{~cm})$ in sites 3, 10 and 19. More Chloroflexi was found in the bottom sediments than in the surface sediments, and it was most abundant in sediments from the 10-25 cm layer (average value 10.42\%). Sediments from the $0-5 \mathrm{~cm}$ layer had a greater abundance of Bacteroidetes than the other layers. Firmicutes in surface sediments $(0-10 \mathrm{~cm})$ from site 3 were in greater abundance than in the bottom sediments $(10-25 \mathrm{~cm})$, while the bottom sediments $(15-25 \mathrm{~cm})$ from site 10 had more Firmicutes than the other layers.

\subsection{Principal component analysis}

PCA was used to study the grouping of the sediment samples from the four seasons (Fig. 6 (a)) and six typical sediments from different layers (Fig. 6 (b)) according to their bacterial community structure. The first two PCA axes explained $87.9 \%$ of total variation in the microbial 
community structure. Bacterial communities in the sediment samples displayed seasonal clustering. Summer and autumn bacterial communities were gathered on the second and third quadrants, and communities from spring and winter appeared in the first and fourth quadrants. The first two PCA axes explained $86.2 \%$ of the total variation in the bacterial community structure of the six typical sediment samples from different layers (Fig. 6 (b)). The bacterial communities in the sediments from layers $(0-15 \mathrm{~cm})$ were gathered on the first, second and fourth quadrants, while the bacterial communities in the bottom sediments $(15-25 \mathrm{~cm})$ were gathered only on the third quadrant.

\subsection{Redundancy analysis}

The RDA results for the relationship between bacterial community composition and environmental factors (physicochemical parameters) at the phylum level are shown in Fig. 7. Samples were taken from different sediment layers in six typical areas: the interpretation rates of the first two RDA axes were $67.05 \%$ and $20.3 \%$, respectively, and the cumulative explanation rate was $87.35 \%$. OM, TP and TN were positively correlated with each other, but pH and DO showed a negative correlation. Some physicochemical parameters influence the bacterial community in lake wetland sediments. Monte Carlo variable tests and permutation experiments indicated that the environmental variable (TP) was statistically significant $(P=0.036$, pseudo- $F=4.1)$ and an important determinant of bacterial community structure. Aminicenantes showed the highest positive correlation with TP concentration. In contrast, Bacteroidetes $(\mathrm{P}<0.01)$ was negatively correlated with TP concentration $($ Table 2$)$.

Table 2

Pearson rank correlation analysis of sediment environmental factors with the abundance of the sediment bacterial community

\begin{tabular}{|c|c|c|c|c|c|c|c|c|c|c|}
\hline & TP & $\mathrm{TN}$ & $\mathrm{pH}$ & OM & DO & Proteobacteria & Firmicutes & Bacteroidetes & Chloroflexi & Nitrospirae \\
\hline TP & 1 & $0.508^{* \star}$ & $0.642^{* *}$ & $0.677^{* k}$ & -0.051 & -0.209 & -0.033 & $-0.544^{* *}$ & -0.194 & -0.094 \\
\hline TN & & 1 & 0.1 & 0.046 & -0.097 & -0.095 & 0.262 & -0.35 & -0.171 & 0.066 \\
\hline $\mathrm{pH}$ & & & 1 & $0.581^{* k}$ & 0.208 & -0.018 & $-0.461^{*}$ & -0.286 & 0.007 & 0.099 \\
\hline $\mathrm{OM}$ & & & & 1 & $0.410^{*}$ & -0.031 & -0.027 & $-0.467^{\star \star}$ & -0.167 & -0.148 \\
\hline DO & & & & & 1 & 0.242 & 0.037 & -0.124 & 0.022 & -0.172 \\
\hline Proteobacteria & & & & & & 1 & 0.205 & -0.067 & -0.233 & -0.185 \\
\hline Firmicutes & & & & & & & 1 & -0.058 & -0.119 & $-0.398^{\star}$ \\
\hline Bacteroidetes & & & & & & & & 1 & -0.119 & 0.133 \\
\hline Chloroflexi & & & & & & & & & 1 & 0.177 \\
\hline Nitrospirae & & & & & & & & & & 1 \\
\hline
\end{tabular}

\subsection{LEfSe analysis based on community abundance}

Figure 8 shows that the bacterial communities dominant in spring were Gammaproteobacteria (the class and orders of Oceanospirillales and Pseudomonadales), Betaproteobacteria (the class and orders of Hydrogenophilales and Nitrosomonadales) and Erysipelotrichia (the class and order of Erysipelotrichales).

The bacterial lineages enriched in summer were Bacteroidia, Deltaproteobacteria, Nitrospirae (from phylum to family), Ignavibacteria (the class and order of Ignavibacteriales), Elusimicrobia (from phylum to order) and Opitutales (the class and order of Opitutaceae).

Eleven groups of bacteria were abundant in autumn: Clostridia, Bacilli (a class from Firmicutes), Planctomycetacia (from class to family), Alphaproteobacteria (the class and orders of Rhodobacterales and Rhizobiales), Caldilineae (the class and order of Caldilineales), Anaerolineae (from class to genus), Flavobacteriia (from class to genus), Thermoleophilia, Coriobacterila, Actinobacteria and Verrucomicrobiae (a class from Verrucomicrobia). 
Nine groups of bacteria mainly belonged to five phyla (Latescibacteria, Cyanobacteria, Caldiserica, Aminicenantes and Spirochaetae) and four orders (Xanthomonadales, Arenicellales, Myxococcales and Desulfobacterales) in winter.

\section{Discussion}

The study area was located in a typical plain river network in the Yangtze River Delta region, China. Industry and economy are developed, and the value of GDP in this area is the highest in China. Exogenous pollution was one of the most significant sources of pollution in this area. Most pollutants were discharged into the lake wetland and large amounts were deposited on the lake wetland sediments. The microbial communities in the sediment has a great influence on the pollutant content, and are important in the transformation and immigration of the pollutants (Huang et al., 2019, Huang and Jiang, 2016). There was considerable variation in the bacterial sediment communities, and they differed between seasons and layers.

The main sources of pollution were printing and dyeing industries, agriculture, and livestock waste, especially around sites $14,18,19$ and 20 . In sediment samples from sites 14, 18, 19 and 20 the highest values of TN, TP and OM contents reached $4847 \mathrm{mg} \mathrm{kg}^{-1}, 1697 \mathrm{mg} \mathrm{kg}{ }^{-1}$ and $17.66 \%$, respectively. There was frequent pollutant entrance and deposition in these areas, and the relative abundance of the bacterial communities in the sediment samples from these four sites was higher than in sediments from sites 3 and 10 (Liu et al., 2009 , Deng et al., 2014). The average concentrations of TN, TP and OM did not vary significantly in lake wetland sediments from different seasons. The TN, TP and $\mathrm{OM}$ in the different regions were higher in winter than in other seasons. This may have been because the low temperature in winter inhibited the activity of the bacterial communities. Reduced rainfall in winter also reduced the concentrations of TN, TP and OM through dilution and biological interception, which weakened the biological removal of TN, TP and OM (Nie et al., 2012, Zhang et al., 2019a).

Most surface sediments in the plain river network area were from the deposition of the pollutants, and the sediments from some sites (such as 3 or 10) have been removed by dredging in recent years. The vertical diversity distribution results indicated that there was greater diversity in the bacterial community in surface sediment samples (Chao, ACE, Shannon) than in the bottom sediments. In addition, pollutant contents in the bottom sediments were low, and the bottom sediments were clearer than the surface sediments, which is one of the main reasons for greater diversity in the surface sediments. On the basis of the richness estimators (Chao and ACE) and the diversity indices (Shannon and Simpson), there were differences in the richness and diversity of the sediment bacterial communities in different seasons. The bacterial community diversity in summer was generally higher than in other seasons owing to the warm environment that favors the growth of microorganisms during this humid season (Zhang et al., 2019b).

Proteobacteria was commonly found to have the greatest relative abundance in sediments, and sedimentary degradation and metabolism mainly relied on this phylum (Chaudhry et al., 2012). Proteobacteria was also the most abundant phylum in all sediment layers, and at greater abundance in the surface sediments than in the bottom sediments. RDA analysis showed that Proteobacteria was negatively correlated with the contents of other environmental variables (TP, TN, OM, DO, PH). Firmicutes predominated in some sediment sites (19); this can generate spores that endure dehydration and harsh environmental states (Huang and Jiang, 2016).

LEfSe analysis showed that Firmicutes were enriched in autumn, and this may have been related to DO and TN levels. The phylum Firmicutes has the ability to perform denitrification processes under anaerobic conditions (Luo et al., 2013). In the bottom sediments Chloroflexi was abundant, while Bacteroidetes was the dominant phylum in the surface sediments. Members of the Chloroflexi are facultative anaerobes and have been identified from freshwater sediments (Kadnikov et al., 2012). They can fit into the changing redox conditions of an aquifer and participate in the degradation of organics, and this action may lead to the low OM content in the sediment (LA et al., 2013, Huang et al., 2017). Bacteroidetes is widespread in a variety of environments such as surface sediments (Vandieken et al., 2017, Orsi et al., 2013, Inagaki, 2015). It is thought to play a vital role in ecosystems because its members process complex molecules into simpler compounds in predominantly anaerobic habitats (Liu et al., 2009, Rosselló-Mora et al., 1999). They are in relatively high concentrations in surface sediment owing to nearby sewage discharge into the lake wetlands, and some of the pollutants from the towns and cities have been deposited into the surface sediments (Liu et al., 2009). Nitrospirae is also an important phylum in the lake wetland sediments and was more abundant on the surface sediments than on the bottom sediments because it is largely dependent on higher oxygen availability (Vetterli et al., 2015). The RDA result indicated that Nitrospirae was negatively correlated with depth, confirming that the phylum prefers aerobic environments.

The 120 surface sediment samples collected in all four seasons and the 30 sediment samples from different layers were obtained in a plain river network in lake wetlands. Large amounts of pollutants were mixed, and some were deposited into the surface sediments (Liu et al., 2009). The highest levels of TN (4847 $\left.\mathrm{mg} \mathrm{kg}^{-1}\right)$, TP (1697 $\mathrm{mg} \mathrm{kg}^{-1}$ ) and OM (17.66\%), and the relative abundance of the bacterial communities in the sediment samples from sites 14, 18, 19 and 20, were higher than in sediments from sites 3 and 10 . The results indicated that the bacterial communities were influenced by environmental factors and that environmental conditions in these areas were complex. 


\section{Conclusion}

The mean pollutants in sediment samples from the lake wetlands did not change significantly over the four seasons. We found a clear difference in microbial diversity, with seasonal shifts, and this diversity was strongly related to sediment depth. We investigated the bacterial communities of sediments from lake wetlands in the plain river network area by high-throughput sequencing method. Proteobacteria was the most abundant phylum in sediments throughout the four seasons. The phylum Chloroflexi was more abundant in the bottom sediments, whereas in the surface sediments the phylum Bacteroidetes was dominant. The physicochemical properties of sediments have a strong influence on the components of a bacterial community. The level of TP had a great influence on the structure of the bacterial community in sediments from lake wetlands, because TP is an important nutrient for living organisms.

\section{Declarations}

\section{Acknowledgement}

This study was supported by the National Natural Science Foundation (52000024, 31500423, and 21906039), Shanghai Sailing Program (20YF1400300), Major Science and Technology Program for Water Pollution Control and Treatment (No. 2017ZX07206), and the Fundamental Research Funds for the Central Universities.

Ethics approval and consent to participate: Not applicable.

Consent for publication: Not applicable.

Availability of data and materials: The datasets used and/or analyzed in the study are available from the corresponding author upon reasonable request.

Competing interests: The authors declare no competing interest.

Funding: This work was supported by the National Natural Science Foundation (52000024, 31500423, and 21906039), Shanghai Sailing Program (20YF1400300), Major Science and Technology Program for Water Pollution Control and Treatment (No. 2017ZX07206), and the Fundamental Research Funds for the Central Universities.

Authors' contributions: Wei Huang: Preparation, creation and/or presentation of the published work, specifically writing the initial draft (including substantive translation); Chengqi Tu and Zhenghai Jin: Provision of study materials, reagents, materials, laboratory samples, instrumentation, computing resources, or other analysis tools. Haoran Yang: Application of statistical, mathematical, computational, or other formal techniques to analyze or synthesize study data. Changyu Lu: Preparation, creation and/or presentation of the published work by those from the original research group, specifically critical review, commentary or revision-including pre-or postpublication stages; Kun Wang: Ideas; formulation or evolution of overarching research goals and aims; Preparation, creation and/or presentation of the published work, specifically writing the initial draft (including substantive translation)

\section{References}

1. Arias ME, Cochrane TA, Kummu M, Lauri H, Holtgrieve GW, Koponen J, Piman T (2014) Impacts of hydropower and climate change on drivers of ecological productivity of Southeast Asia's most important wetland. Ecol Model 272:252-263

2. Bunn SE, Abal EG, Smith MJ, Choy SC, Fellows CS, Harch BD, Kennard MJ, Sheldon F (2010) Integration of science and monitoring of river ecosystem health to guide investments in catchment protection and rehabilitation. Freshw Biol 55:223-240

3. Chaudhry V, Rehman A, Mishra A, Chauhan PS, Nautiyal CS (2012) Changes in bacterial community structure of agricultural land due to long-term organic and chemical amendments. Microb Ecol 64:450-460

4. Chen N, Yang JS, Qu JH, Li HF, Liu WJ, Li BZ, Wang ET, Yuan HL (2015) Sediment prokaryote communities in different sites of eutrophic Lake Taihu and their interactions with environmental factors. World J Microbiol Biotechnol 31:883-896

5. Cookson WR, O'Donnell AJ, Grant CD, Grierson PF, Murphy DV (2008) Impact of ecosystem management on microbial community level physiological profiles of postmining forest rehabilitation. Microb Ecol 55:321-332

6. de Oliveira LF, Margis R (2015) The source of the river as a nursery for microbial diversity. PLoS ONE 10:e0120608

7. Deng YC, Cui XY, Hernandez M, Dumont MG (2014) Microbial Diversity in Hummock and Hollow Soils of Three Wetlands on the QinghaiTibetan Plateau Revealed by 16S rRNA Pyrosequencing. PLoS ONE 9:10

8. Hall JR, Mitchell KR, Jackson-Weaver O, Kooser AS, Cron BR, Crossey LJ, Takacs-Vesbach CD (2008) Molecular characterization of the diversity and distribution of a thermal spring microbial community by using rRNA and metabolic genes. Appl Environ Microbiol 74:4910- 
4922

9. Huang W, Chen X, Jiang X, Zheng B (2017) Characterization of sediment bacterial communities in plain lakes with different trophic statuses. Microbiologyopen 6:e503

10. Huang W, Chen X, Wang K, Chen J, Zheng B, Jiang X (2019) Comparison among the microbial communities in the lake, lake wetland, and estuary sediments of a plain river network. MicrobiologyOpen 8:e644

11. Huang W, Jiang X (2016) Profiling of Sediment Microbial Community in Dongting Lake before and after Impoundment of the Three Gorges Dam. International Journal of Environmetal Research and Public Health 13:617

12. Huang W, Lu Y, Li J, Zheng Z, Zhang J, Jiang X (2015) Effect of ionic strength on phosphorus sorption in different sediments from a eutrophic plateau lake. RSC Adv 5:79607-79615

13. Inagaki F, Hinrichs KU, Kubo Y, Bowles MW, Heuer VB, Hong WL et al (2015) Exploring deep microbial life in coal-bearing sediment down to $\sim 2.5 \mathrm{~km}$ below the ocean floor. Science 349:420-424

14. Kadnikov VV, Mardanov AV, Beletsky AV, Shubenkova OV, Pogodaeva TV, Zemskaya TI, Ravin NV, Skryabin KG (2012) Microbial community structure in methane hydrate-bearing sediments of freshwater Lake Baikal. FEMS Microbiol Ecol 79:348-358

15. Laura H, Cindy JC, Kelly CW, Brian CT, Itai S, Kyle RF, Kenneth HW, Susannah GT, Jillian FB (2013) Community genomic analyses constrain the distribution of metabolic traits across the Chloroflexi phylum and indicate roles in sediment carbon cycling. Microbiome 1:22-39

16. Lin X, Green S, Tfaily MM, Prakash O, Konstantinidis KT, Corbett JE, Chanton JP, Cooper WT, Kostka JE (2012) Microbial community structure and activity linked to contrasting biogeochemical gradients in bog and fen environments of the Glacial Lake Agassiz Peatland. Appl Environ Microbiol 78:7023-7031

17. Liu D, Ding W, Jia Z, Cai Z (2012) The impact of dissolved organic carbon on the spatial variability of methanogenic archaea communities in natural wetland ecosystems across China. Appl Environ Microbiol 96:253-263

18. Liu FH, Lin GH, Gao G, Qin BQ, Zhang JS, Zhao GP, Zhou ZH, Shen JH (2009) Bacterial and archaeal assemblages in sediments of a large shallow freshwater lake, Lake Taihu, as revealed by denaturing gradient gel electrophoresis. J Appl Microbiol 106:1022-1032

19. Liu Z, DeSantis TZ, Andersen GL, Knight R (2008) Accurate taxonomy assignments from 16S rRNA sequences produced by highly parallel pyrosequencers. Nucleic Acids Res 36:e120

20. Luo J, Liang H, Yan L, Ma J, Yang Y, Li G (2013) Microbial community structures in a closed raw water distribution system biofilm as revealed by 454-pyrosequencing analysis and the effect of microbial biofilm communities on raw water quality. Bioresour Technol 148:189-195

21. Mackelprang R, Waldrop MP, DeAngelis KM, David MM, Chavarria KL, Blazewicz SJ, Rubin EM, Jansson JK (2011) Metagenomic analysis of a permafrost microbial community reveals a rapid response to thaw. Nature 480:368-U120

22. Mayor DJ, Thornton B, Hay S, Zuur AF, Nicol GW, McWilliam JM, Witte UF (2012) Resource quality affects carbon cycling in deep-sea sediments. ISME J 6:1740-1748

23. Moseman-Valtierra SM, Armaiz-Nolla K, Levin LA (2010) Wetland response to sedimentation and nitrogen loading: Diversification and inhibition of nitrogen- fixing microbes. Ecol Appl 20:1556-1568

24. Newman S (2011) Wetland Ecology: Principles and Conservation, 2nd Edition. Journal of Environmental Quality 40: $1345-1345$

25. Newton RJ, Jones SE, Eiler A, McMahon KD, Bertilsson S (2011) A guide to the natural history of freshwater lake bacteria. Microbiol Mol Biol Rev 75:14-49

26. Nie Z, Liang X, Xing B, Ye Y, Qian Y, Yu Y, Bian J, Gu J, Liu J, Chen Y (2012) The current water trophic status in Tiaoxi River of Taihu Lake watershed and corresponding coping strategy based on N/P ratio analysis. Acta Ecol Sin 32:48-55

27. Obi CC, Adebusoye SA, Ugoji EO, Ilori MO, Amund OO, Hickey WJ (2016) Microbial Communities in Sediments of Lagos Lagoon, Nigeria: Elucidation of Community Structure and Potential Impacts of Contamination by Municipal and Industrial Wastes. Front Microbiol 7:16

28. Orsi WD, Edgcomb VP, Christman GD, Biddle JF (2013) Gene expression in the deep biosphere. Nature 499:205-208

29. Paradis E, Claude J, Strimmer K (2004) APE: Analyses of Phylogenetics and Evolution in R language. Bioinformatics 20:289-290

30. Redmond MC, Valentine DL (2012) Natural gas and temperature structured a microbial community response to the Deepwater Horizon oil spill. PNAS 109:20292-20297

31. Rosselló-Mora R, Thamdrup B, Schäfer H, Weller R, Amann R (1999) The Response of the Microbial Community of Marine Sediments to Organic Carbon Input under Anaerobic Conditions. Syst Appl Microbiol 22:237-248

32. Schwarz JIK, Eckert W, Conrad R (2007) Community structure of Archaea and Bacteria in a profundal lake sediment Lake Kinneret (Israel). Syst Appl Microbiol 30:239-254

33. Segata N, Izard J, Waldron L, Gevers D, Miropolsky L, Garrett WS (2011) Huttenhower Metagenomic biomarker discovery and explanation. Genome Biology 12 
34. Song H, Li Z, Du B, Wang G, Ding Y (2012) Bacterial communities in sediments of the shallow Lake Dongping in China. J Appl Microbiol 112:79-89

35. Vandieken V, Marshall IPG, Niemann H, Engelen B, Cypionka H (2017) Labilibaculum manganireducens gen. nov., sp. nov. and Labilibaculum filiforme sp. nov., Novel Bacteroidetes Isolated from Subsurface Sediments of the Baltic Sea. Front MicrobiolOGY 8:2614

36. Vetterli A, Hyytiainen K, Ahjos M, Auvinen P, Paulin L, Hietanen S, Leskinen E (2015) Seasonal patterns of bacterial communities in the coastal brackish sediments of the Gulf of Finland, Baltic Sea. Estuarine Coastal and Shelf Science 165:86-96

37. Wan Y, Ruan X, Zhang Y, Li R (2017) Illumina sequencing-based analysis of sediment bacteria community in different trophic status freshwater lakes. Microbiologyopen 6:e450

38. Wang Y, Qian PY (2009) Conservative Fragments in Bacterial 16S rRNA Genes and Primer Design for 16S Ribosomal DNA Amplicons in Metagenomic Studies. PLoS ONE 4:e7401

39. Wang Y, Sheng HF, He Y, Wu JY, Jiang YX, Tam NFY, Zhou HW (2012) Comparison of the Levels of Bacterial Diversity in Freshwater, Intertidal Wetland, and Marine Sediments by Using Millions of Illumina Tags. Appl Environ Microbiol 78:8264-8271

40. Yang Y, Dai Y, Wu Z, Xie S, Liu Y (2016) Temporal and Spatial Dynamics of Archaeal Communities in Two Freshwater Lakes at Different Trophic Status. Frontiers Microbiology 7:451

41. Yu C, Zhang J, Wu L, Liu YZ, Ge G (2015) Effects of Heavy Metal and Nutrients on Benthic Microbial Communities in Freshwater Sediment of Poyang Lake (China). Journal of Residuals Science \& Technology 12:105-111

42. Zhang L, Zhao TT, Shen TT, Gao G (2019a) Seasonal and spatial variation in the sediment bacterial community and diversity of Lake Bosten, China. J Basic Microbiol 59:224-233

43. Zhang MZ, Wu ZJ, Sun QY, Ding YX, Ding ZW, Sun LL (2019b) The spatial and seasonal variations of bacterial community structure and influencing factors in river sediments. J Environ Manage 248:109293

\section{Figures}




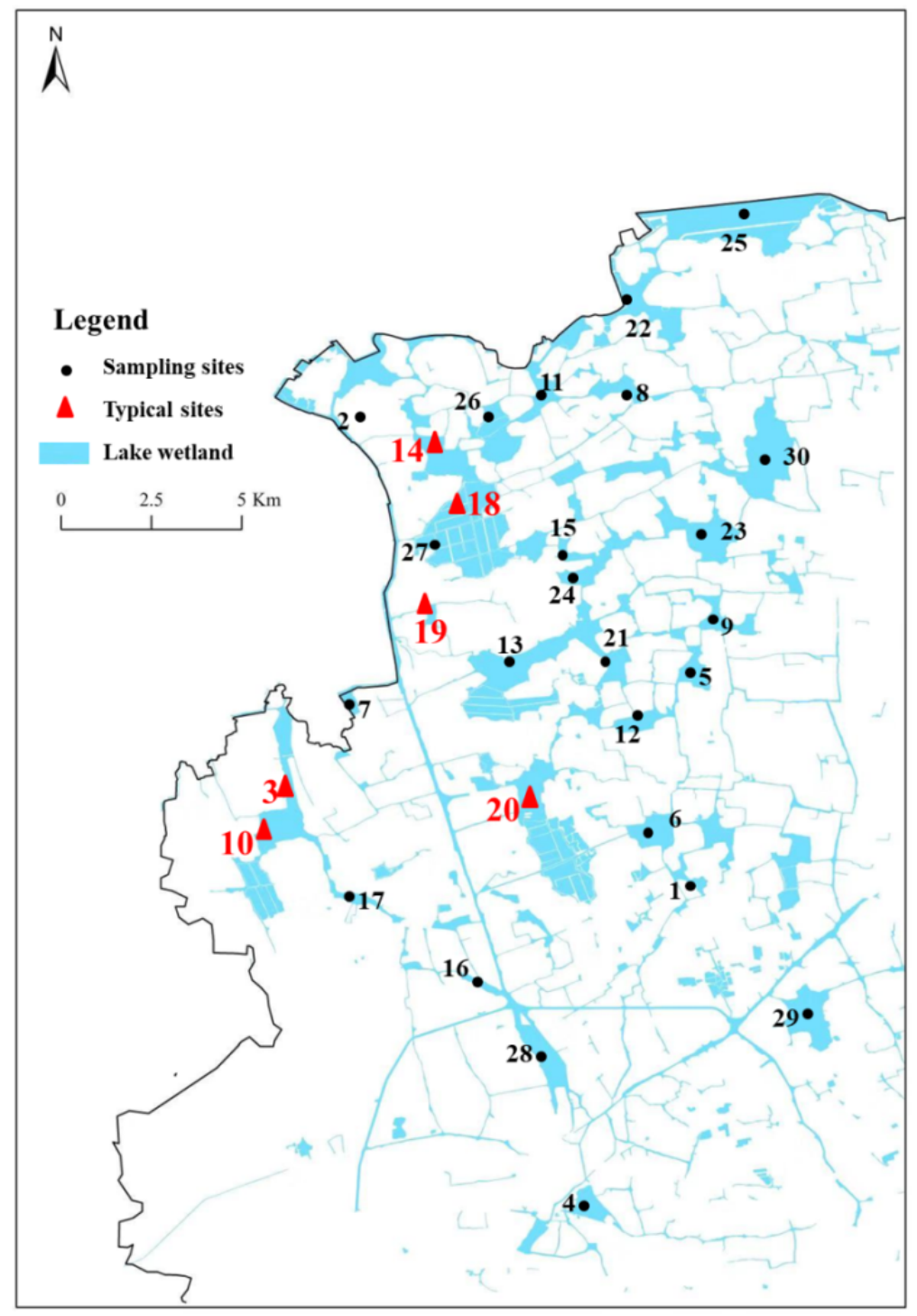

Figure 1

Sampling sites and the six typical sites 

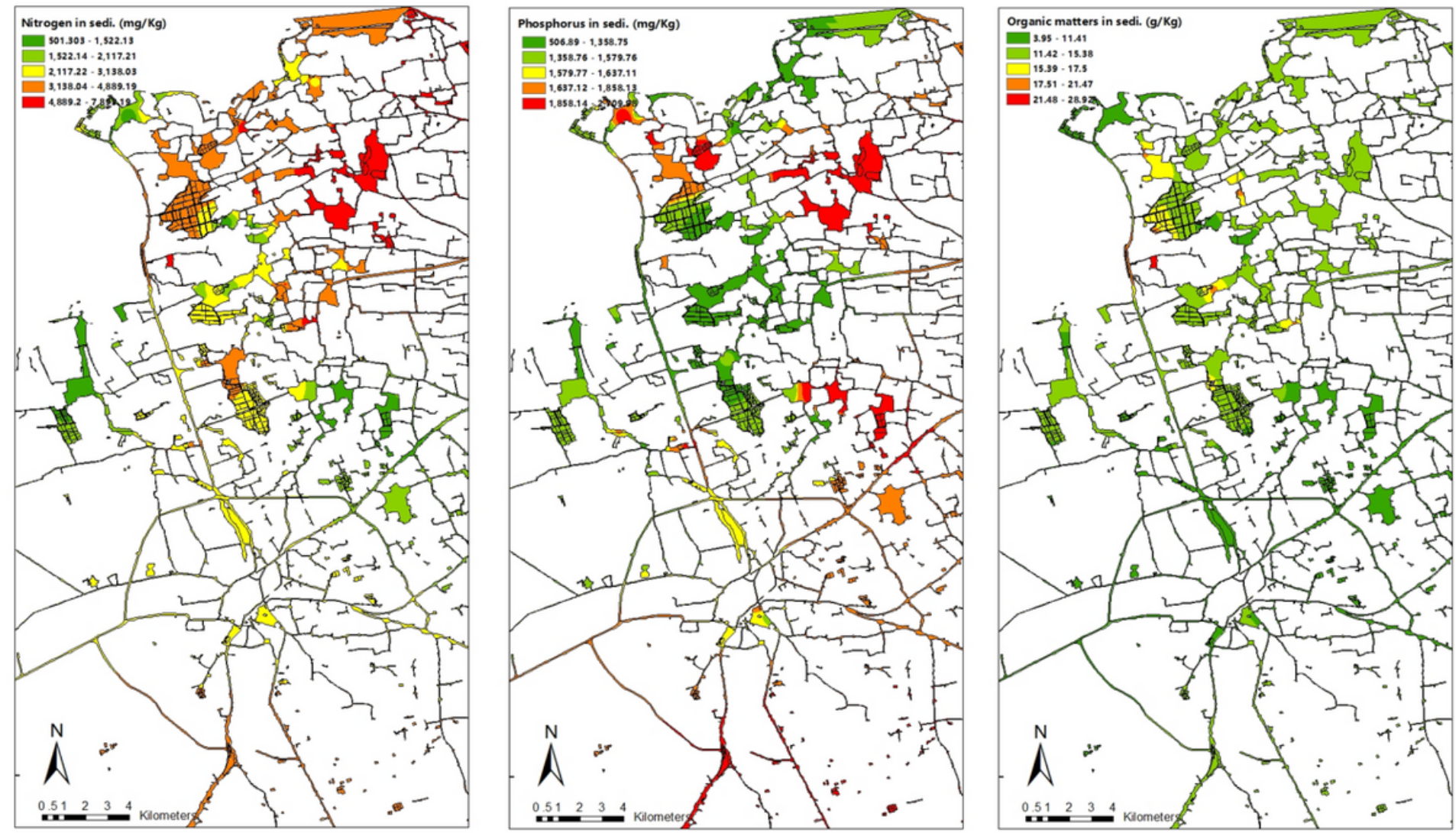

Figure 2

Spatial distribution of pollutants (total nitrogen, TN; total phosphorus, TP; and organic matter, OM) in the lake wetlands 

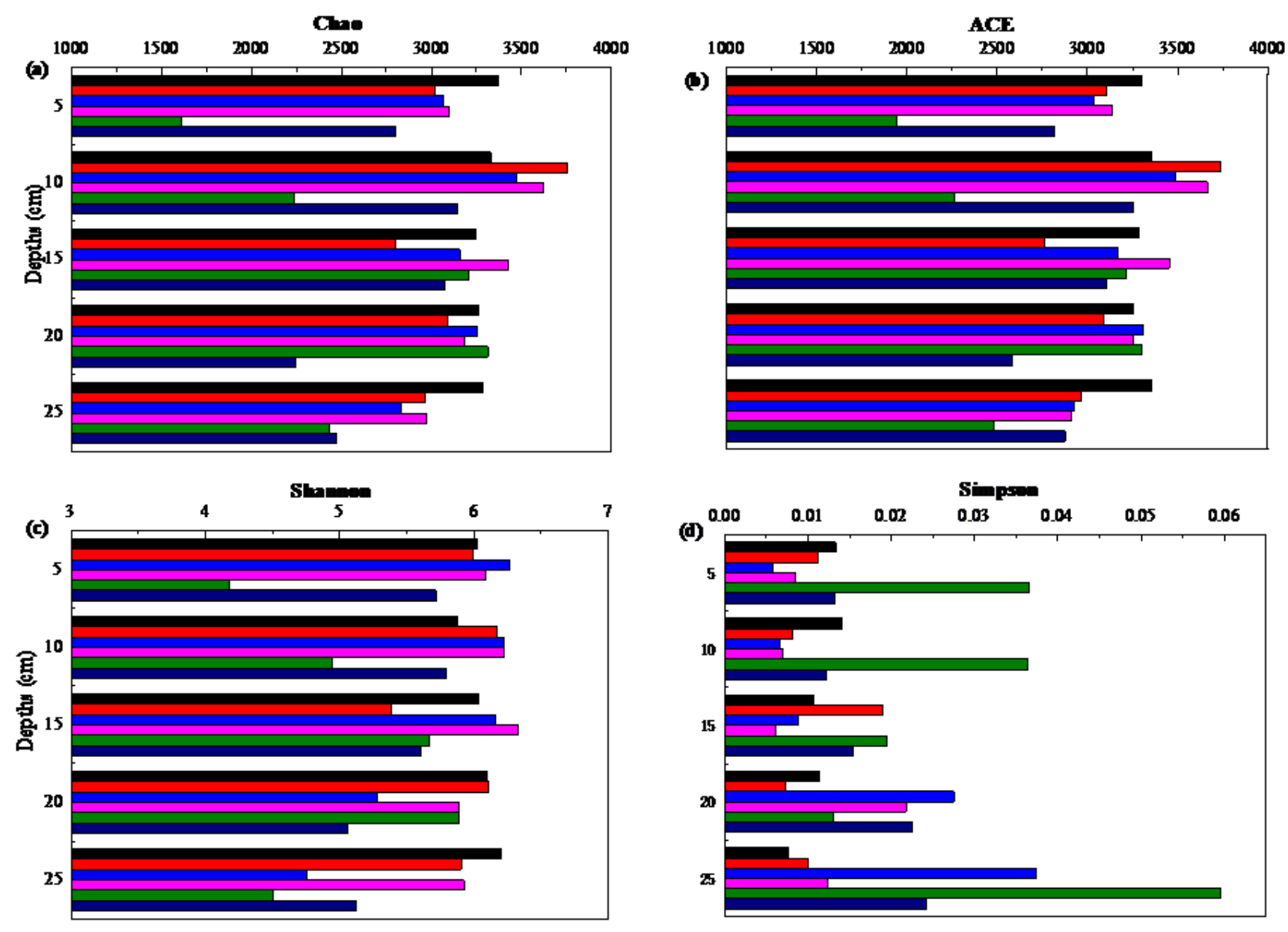

$3 \square 10 \square 14 \square 18 \square 19 \square 20$

Figure 3

The diversity indices of the sediment samples from six typical sites $(3,10,14,18,19,20)$ were divided into five layers (0-5, 5-10, $10-15,15-$ $20,20-25 \mathrm{~cm}$ ) in summer respectively) 

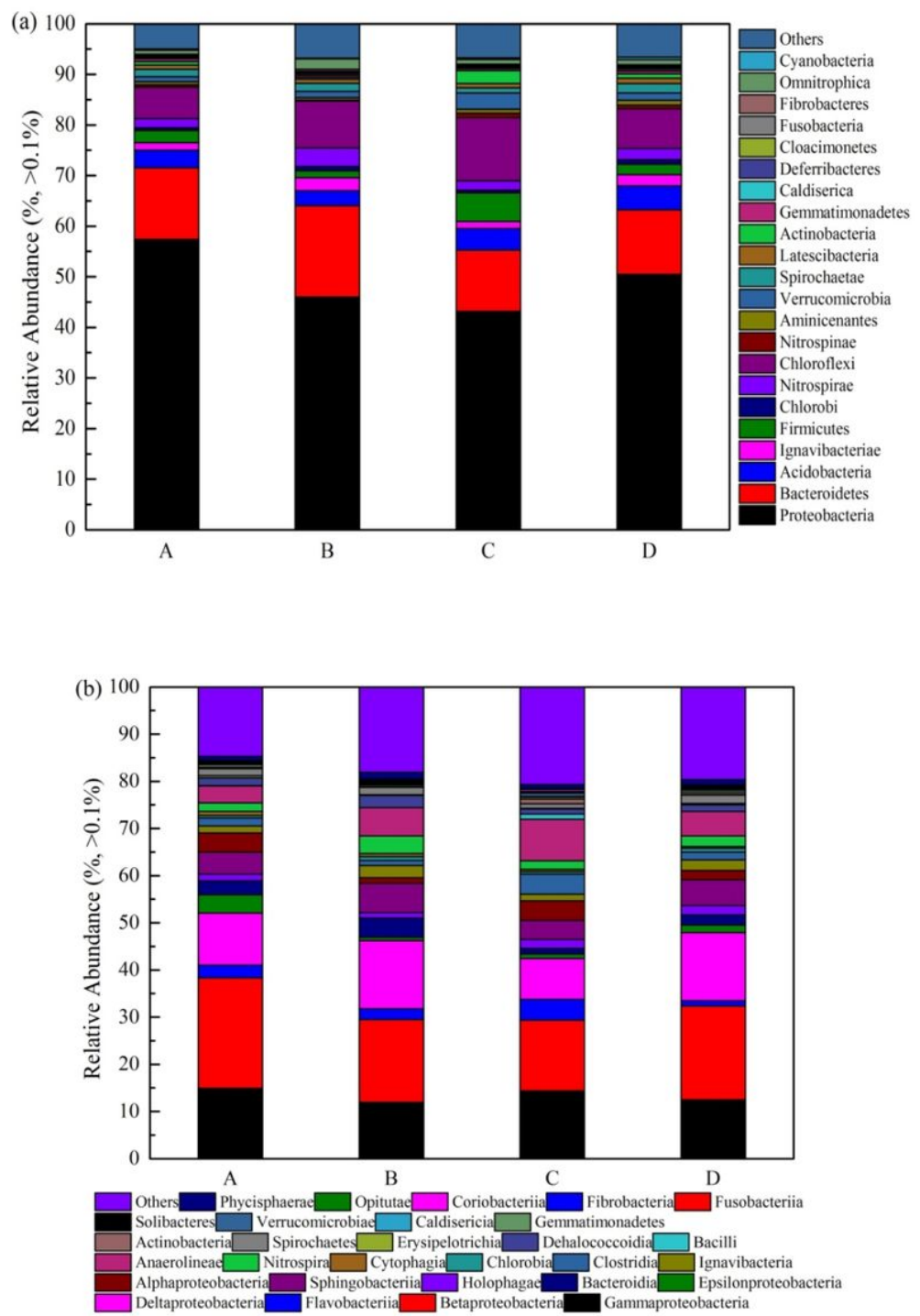

Figure 4

Relative abundances of different phyla (a) and classes (b) in 120 sediment samples from four seasons (A for spring, B for summer, C for autumn and $\mathrm{D}$ for winter) 
Relative Abundance ( $\%,>0.1 \%)$
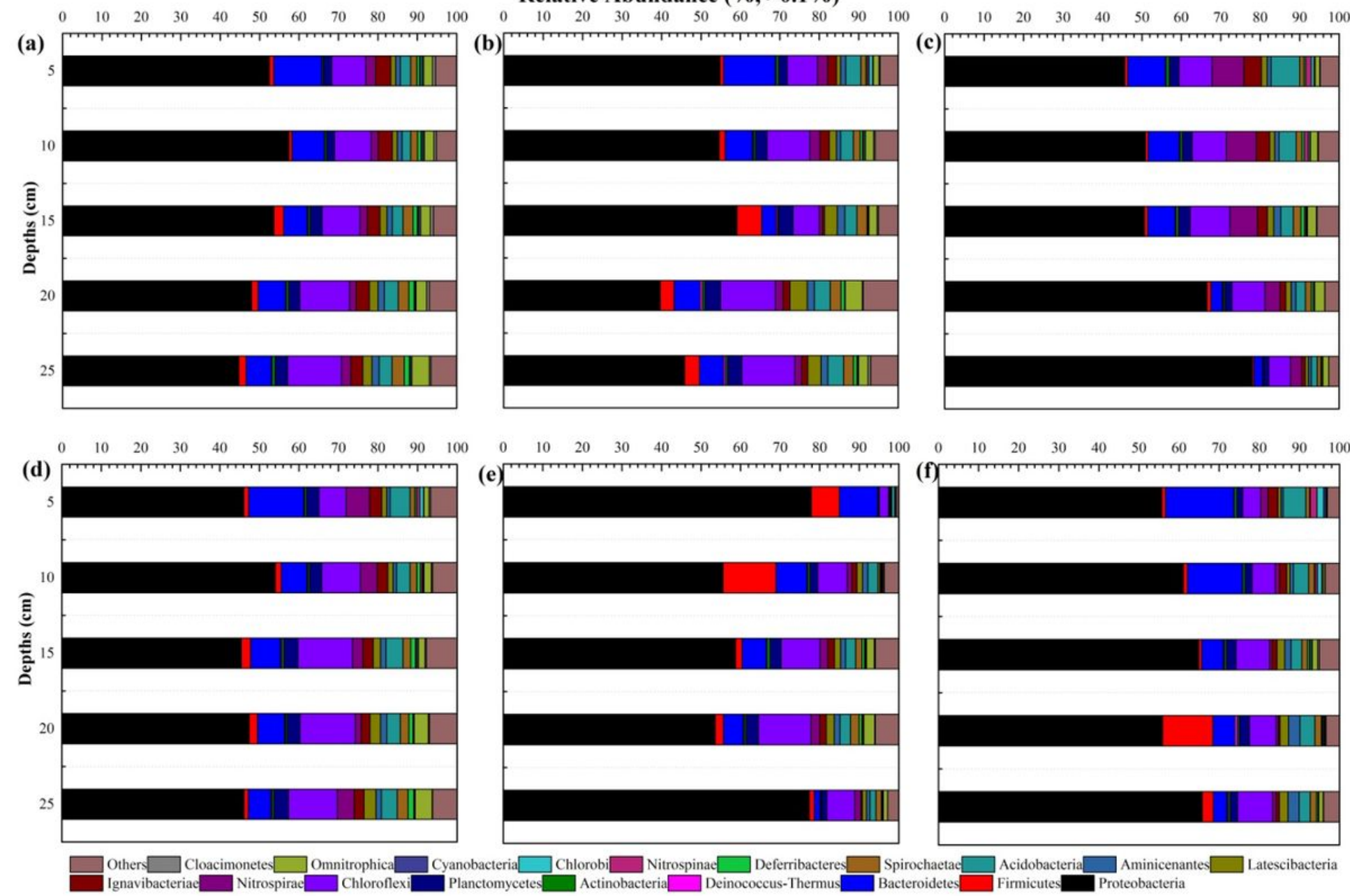

Figure 5

Relative abundances of different phyla in 30 sediment samples from six typical sites $(3,10,14,18,19,20)$ divided into five layers $(0-5,5-10$, $10-15,15-20,20-25 \mathrm{~cm})$ 

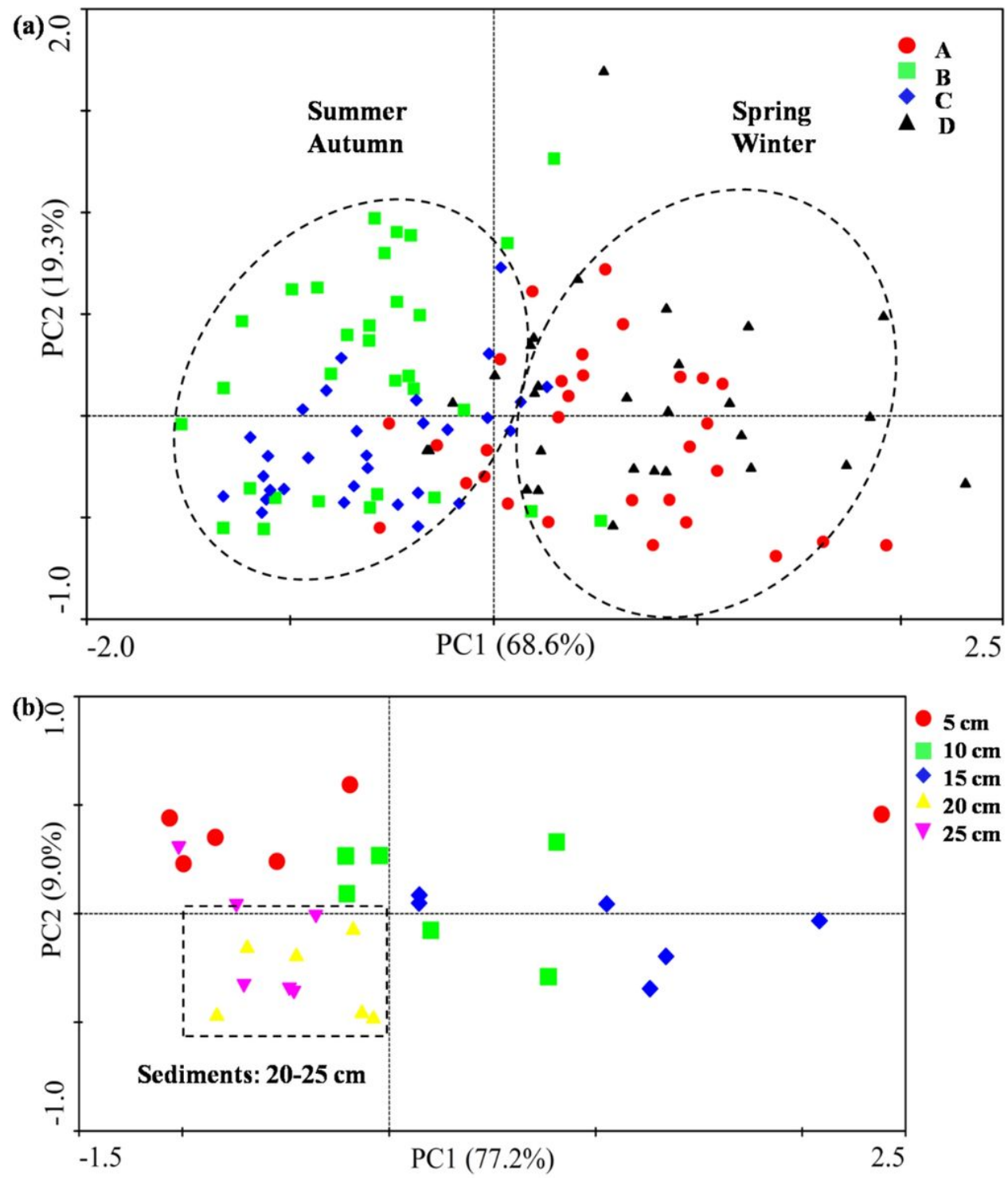

Figure 6

(a) Ordination plot showing grouping of sediment samples from the four seasons according to their bacterial community structure; (b) ordination plot showing grouping of sediment samples from different depths according to their bacterial community structure 


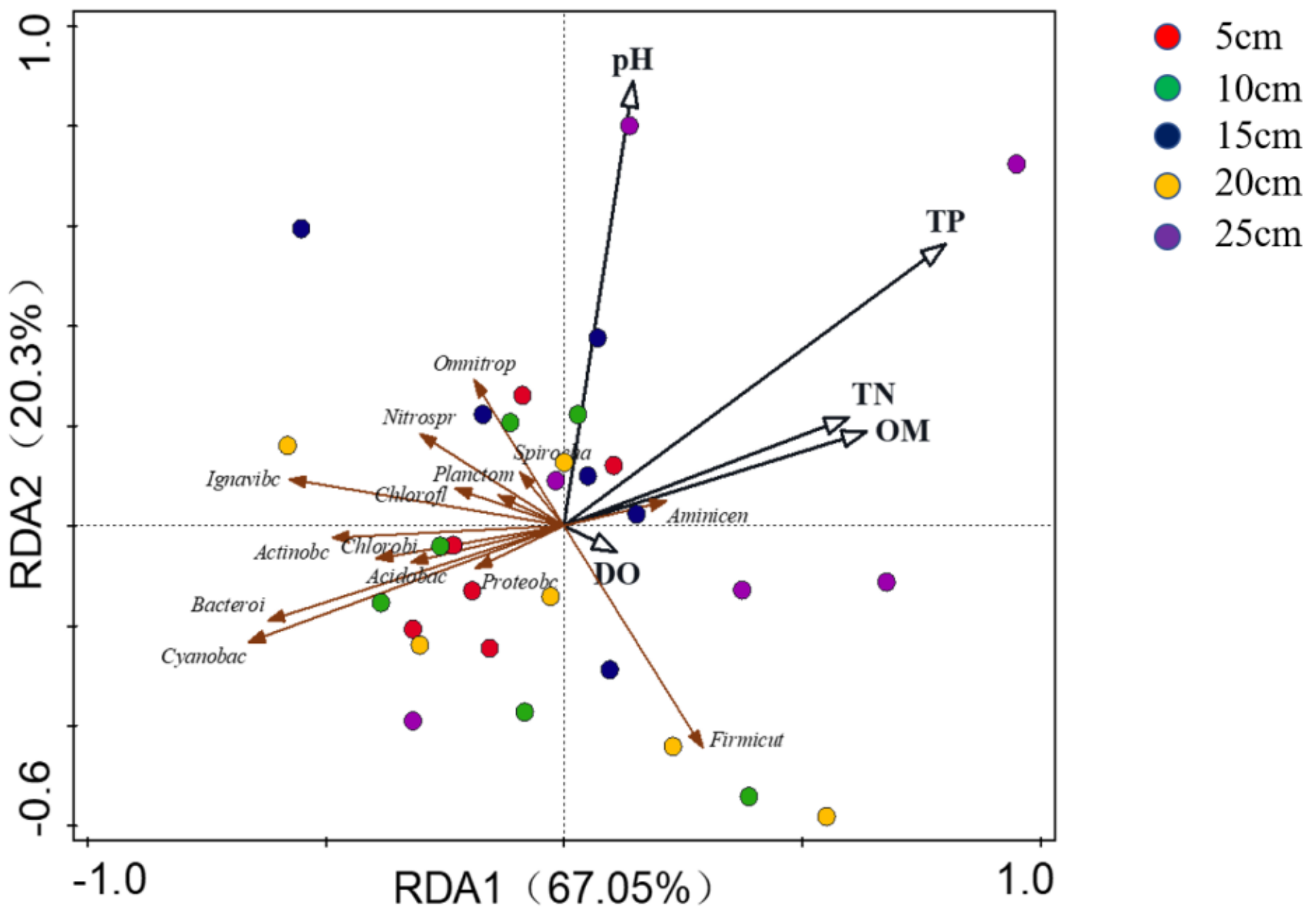

Figure 7

Redundancy analysis (RDA) of the bacterial communities as affected by environmental conditions and based on the relative abundance of dominant bacterial phyla (dots of different colors represent different depths)

\section{Cladogram}

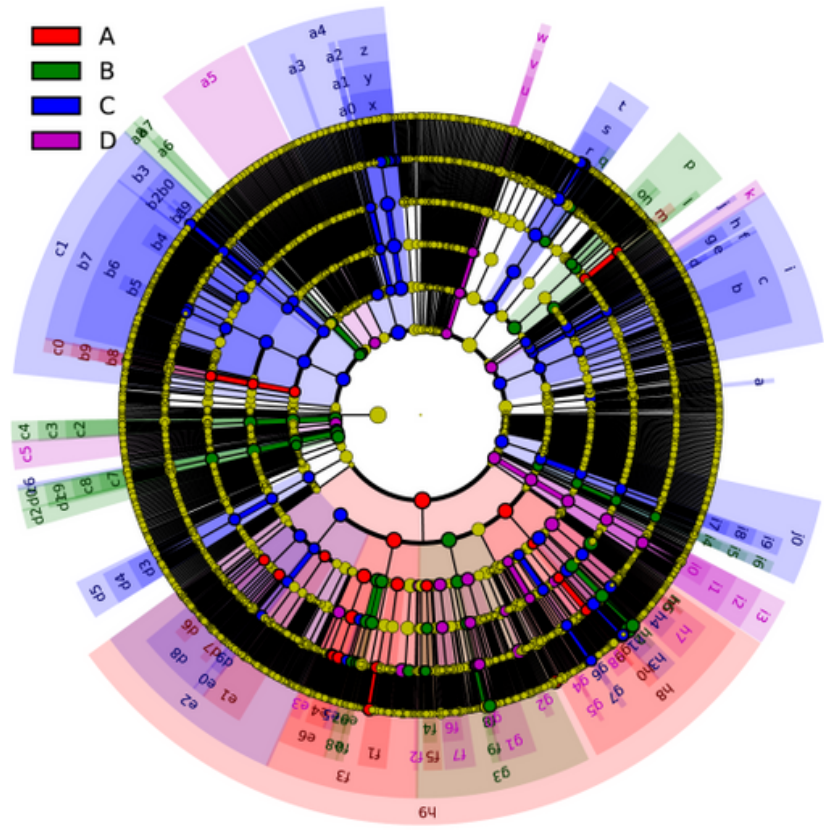

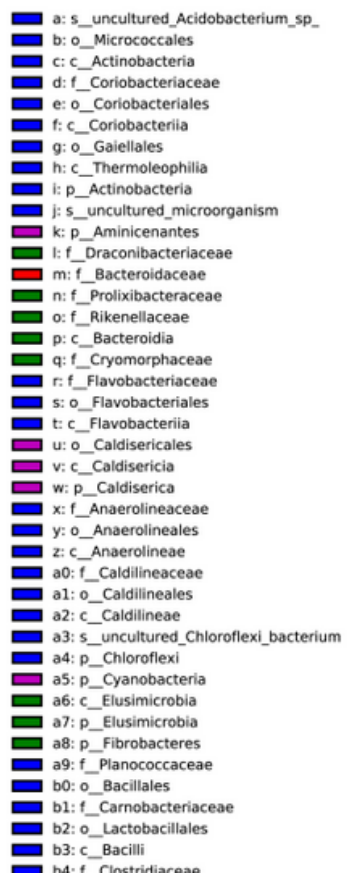

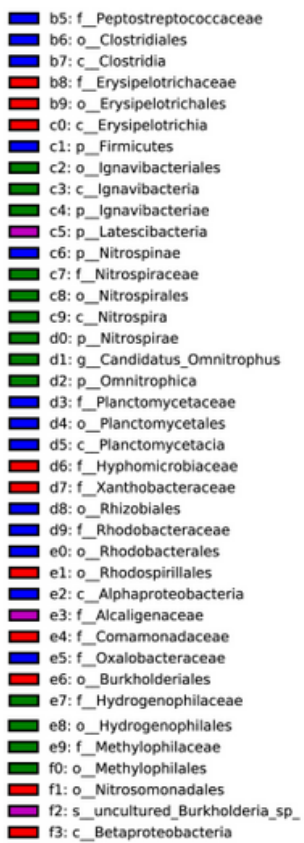

Page 16/17

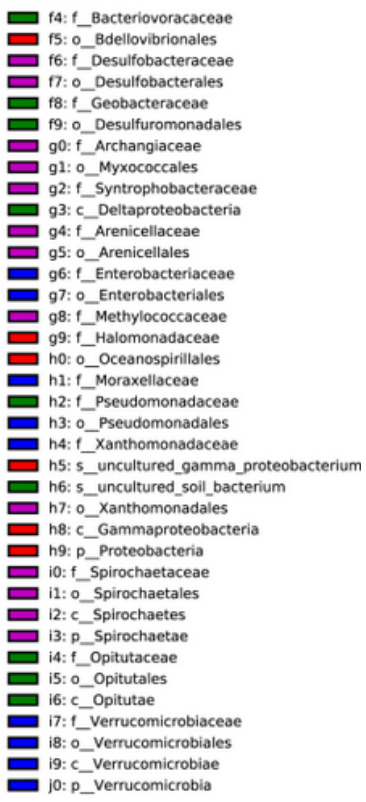




\section{Figure 8}

Cladograms showing the differences in relative abundance of bacterial communities in the four seasons according to the linear discriminant analysis effect size (LEfSe) analysis with LDA values of 3. Differences are represented by the color of the most abundant class (A for spring, B for summer, $C$ for autumn and $D$ for winter). The diameter of each circle is proportional to a taxon's abundance. The circles from inner region to outer region represent the phylogenetic levels from domain to genus 